\title{
The Effects of Scientific Self-efficacy and Cognitive Anxiety on Science Engagement with "Question- Observation-Doing-Explanation" Model during Schools Disruption in COVID-19 Pandemic
}

\section{Xiantong Yang}

Capital Normal University

Mengmeng Zhang

Beijing Normal University

Lingqiang Kong

Shandong Feicheng Teaching Research Center

Qiang Wang ( $\sim$ qwchem@gmail.com )

Capital Normal University

Jon-Chao Hong

National Taiwan Normal University

\section{Research Article}

Keywords: Distance education, Online learning, Mobile learning, Learning strategies, Science learning

Posted Date: July 10th, 2020

DOI: https://doi.org/10.21203/rs.3.rs-40814/v1

License: (c) (i) This work is licensed under a Creative Commons Attribution 4.0 International License. Read Full License

Version of Record: A version of this preprint was published at Journal of Science Education and Technology on November 4th, 2020. See the published version at https://doi.org/10.1007/s10956-02009877-x. 


\section{Abstract}

The game-based learning supported by mobile intelligence technology has promoted the renewal of teaching and learning model. Therefore, a model of Question-Observation-Doing-Explanation (QODE) based on smart phones was constructed and applied to the science learning during school disruption in COVID-19 pandemic. In this study, from the theoretical perspective of Cognitive-affective Theory of Learning with Media, Bandura's Motivation Theory and Community of Inquiry model, self-report measure was used to verify the effect of students' scientific self-efficacy and cognitive anxiety on science engagement. 357 valid questionnaires were used for structural equation model research. The results of this study indicated that two types of scientific self-efficacy as indicated by scientific leaning ability and scientific learning behavior was negatively associated with cognitive anxiety. In addition, cognitive anxiety was also negatively correlated to four types of science engagement as indicated by cognitive engagement, emotional engagement, behavioral engagement and social engagement through smartphone interactions. These findings provide further evidence for game-based learning promoted by smart phones, contributing to deeper understanding of the associations between scientific self-efficacy, cognitive anxiety and science engagement. The implication of this study pointed out that the QODE model is suitable for implementing at a smart mobile device to students' science learning.

\section{Introduction}

Affected by the new coronavirus, many countries require schools to suspend classes in order to stop the spread of the virus, which challenges the normal schooling of 370 million students around the world (UNESCO 2020). It is noteworthy that the long-term isolation has made students face multiple difficulties in online learning. Among them, the unknown serious infectious diseases have induced students to get serious stress responses (Samantha Kelly et al. 2018; Seyle 1956). In particular, COVID- 19 seriously threatens the health of students and leads to anxiety and depression, which may affect the learning engagement of students isolated at home (Junfeng et al. 2020; Selcuk and Sukriye 2020). These

negative emotions such as anxiety may influence the memory effect and academic progress of students' learning at home (Kizilbash et al. 2002; Yeh 2007). Engagement and interaction between teachers and students during online learning are critical for students to construct an understanding of new knowledge (Zhu 2006). However, the distance learning led to poor interaction effect and low learning investment during epidemic (Garrison et al. 2001; Kanuka and Anderson 1998). All the above problems need to be improved urgently to accelerate students' learning engagement.

According to the Community of Inquiry (Col) model (Garrison et al. 1999; Remesal and Friesen 2014), learning takes place in the community through the interaction of cognitive presence, social presence and teaching presence. First, learning participants construct meaning through continuous critical reflection and dialogue in the inquiry learning community (Garrison 2011). Second, learners project themselves to 
Col, using media to show real themselves in social and emotional aspects (Garrison et al. 1999). Third, teaching presence promotes and guides learners' cognition and social process, helping learners achieve the learning effect of personal meaning and educational value (Garrison et al. 2001). Many studies have found that the model of Col can improve the interaction of members by creating an open inquiry learning atmosphere and strengthen community cohesion (Amanda et al. 2016; Selcan and Zahide 2018).

It has been also found that the inquiry project supported by technology can link the antecedents and consequences of students' behavior, feeling and thinking mode so as to improve students' learning engagement (Mcconney et al. 2014; Jrvel et al. 2008). However, Pedaste et al. (2015) proposed that the validity of inquiry learning models would vary depending on the different educational context. Previous research models were all based on specific learning background, such as the $5 \mathrm{E}$ learning model proposed by Bybee et al. (2006), POE inquiry learning model proposed by Hong et al. (2014) and the five-step inquiry cycle proposed by White and Frederiksen (1998). However, the value of Doing of inquiry was not reflected in the previous model. Learning-by-doing was emphasized as one of the important concepts of educational constructivism over a period of time (Taylor et al. 2004). Learning-by-doing environments promoted participants' physical, social and cognitive engagement in project (Edelson 1999; Gardner 2011; Papert 1980). Thus, this research developed the Question-Observation-Doing-Explanation (QODE) inquiry model which highlighted the value of Doing in the process of problem-based inquiry. Finally, due to the domain specificity of learning engagement (Martin 2008), this study aimed to verify the effect of QODE model during students' science learning engagement in combination with the background of science subjects. Meanwhile, the purpose of this study was also to explore how cognitive anxiety and scientific self-efficacy affect students' learning engagement in the context of the epidemic.

\section{Theoretical Background}

Learning engagement is a positive, substantial, stable and lasting mental state related to learning, (Schaufeli et al. 2002). Learning engagement is not only an important predictor of academic achievement,

but also an effective observation index to measure learning quality and predict the development and growth of students (Christenson et al. 2012; Liu et al. 2017; Zhen et al. 2016). Although researcher have confirmed that learning engagement is domain specific (Martin 2008), there are still sporadic researches on learning engagement in the context of science, so it is necessary to study the factors that affect students' learning engagement in the epidemic situation.

Based on Bandura's Motivation Theory (Bandura and Schunk 1981; Bandura 1993), Cognitive- affective Theory of Learning with Media (CATLM) (Moreno 2006, 2009) and Theory of Col (Garrison 2011; Garrison and Akyol 2015), self-efficacy and cognitive anxiety are considered as the critical interactive psychology variable to explore science learning engagement. 


\section{Leaning under the COVID-19 pandemic}

COVID-19 refers to pneumonia caused by 2019 novel coronavirus infection. As of July 1, 2020, it has infected more than 10 million people worldwide (WHO, 2020). As a serious infectious disease, COVID- 19 can cause anxiety and other stress symptoms in the population. The long-term isolation at home and the suspension of production made the adverse impact of the epidemic more serious. Among them, the global students from the offline school to online learning, which posed a serious challenge to the current online education.

According to the stress theory put forward by the Selye (1950), stress is a state manifested through special syndrome, including all changes caused by non-specific in biological system. Stressor refers to the stimulus factors that cause the stress response of the body (Selye 1952; Seyle 1956), including positive life events and negative life events. COVID-19 is a negative social stressor, which will seriously threaten the health and safety of individuals. When stressors act on students, students always adopt physiological and psychological defense measures consciously or unconsciously in order to maintain their own psychological balance. Among them, anxiety is a process in which individuals respond appropriately to stress psychologically. Appropriate anxiety is conducive to enhancing the response speed and alertness of the brain, thus improving learning efficiency and satisfaction (Chen 2019; Hordacre et al. 2016), while excessive anxiety reduces students' learning engagement and academic performance (Khng and Hui 2016; Ramirez et al. 2016; Scanlon et al. 2020; Shu-Yun Sophie 2013; Soltanlou et al. 2019). The impact of COVID-19 on students' home-based learning may be complex, so empirical research is needed to provide evidence to support students' home-based learning.

\section{Determinants of cognitive anxiety: leaning self-efficacy}

Anxiety is a complex emotional state of tension, uneasiness, worry and other unpleasant feelings caused by an individual's coming and possible threat (Bauer and Julius 1965). Spielberger (1972) divided anxiety into trait anxiety and state anxiety. Martens et al. (1990) pointed out that state anxiety is domain specific and contains multiple dimensions. On this basis, Weinberg and Gould (2003) classified its

subcomponents as cognitive and psychological anxiety. Hence, cognitive anxiety (CA) can be considered as a psychological component of state anxiety. It had been found (Hong et al. 2017) that CA was a key variable affecting self-confidence in the process of learning science through media. In conclusion, it is reasonable to study CA as a sub-dimension of anxiety because this study aims to explore the impact of 
multimedia learning environment on students' learning science under the influence of epidemic situation based on CATLM.

According to Bandura's Motivation Theory (Bandura 1982), the learning self-efficacy can be defined as people's subjective judgment on whether they can succeed in learning. The learning behavior of human beings is influenced by the result factors and antecedent factors of behavior, the result factors of behavior are the expectation of learning results, and the antecedent factors of behavior are the expectation of learning efficiency (Bandura 1989). When people are convinced that they are capable of learning science, then they will have a high sense of self-efficacy to participate in learning activities (Britner and Pajares 2006). Combining previous arguments (Gibson and Dembo 1984; Kairong et al. 1999), science self- efficacy could be divided into two types: self-efficacy of science leaning ability (SSLA) and self-efficacy of science leaning behavior (SSLB). The SSLA refers to an individual's judgment and confidence on whether he has the learning ability to successfully complete his studies, get good grades and avoid academic failure. The SSLB refers to the individual's judgment and confidence on whether he can adopt certain learning methods to achieve the learning goal.

Current research found that emotion arise is related to the formation of self-efficacy, high emotional arousal and tense physiological state could hinder behavior operation and reduce individual's expectation of success (Brígido et al. 2013; Holstermann et al. 2009). Specifically, people with high level of anxiety tend to underestimate their ability. When people are in a state of excessive anxiety, anxiety will interact with fear to generate a vicious circle, which will eventually strengthen the sense of incompetence (Neng et al. 2018; Valentiner et al. 1996). At present, there are many researches on self-efficacy and general anxiety, but there is still a lack of research on the effect of scientific learning self-efficacy on CA. In order to explore the influence of COVID-19 on students' self-efficacy in science learning, this study attempts to explore the relationship between self-efficacy in science learning and CA based on the research of general self-efficacy in Bandura's Motivation Theory. Hence, the following assumptions are proposed.

H1. SSLA is negatively correlated with CA.

H2. SSLB is negatively correlated with CA.

\section{Determinants of science leaning engagement: cognitive anxiety}

As an important indicator to measure students' learning performance, learning engagement has been widely concerned by researchers in recent year (Johnson and Sinatra 2013; Skinner et al. 2009; Zhen et al. 2017). Learning engagement mainly refers to the social extent, behavior intensity, emotional quality 
and the use of cognitive strategies of students involved in learning activities. It was generally divided into four dimensions: cognitive engagement, emotional engagement, behavior engagement and social engagement (Finn and Zimmer 2012; Fredricks et al. 2004; Fredricks et al. 2016; Lam et al. 2012; Rimmkaufman et al. 2014). It was found that learning engagement get certain domain specificity, and the same learners' learning engagement of different subjects has diversities (Martin 2008). At present, most of the researches focused on the study of general learning engagement, but few studies of learning engagement were concern to in scientific context. Scientific learning plays an important role in the development of students' logical thinking, spatial cognition and other abilities (Floyd et al. 1992; Lynn 2000; Lynn et al. 2011). Therefore, to study the influencing factors and mechanism of science learning engagement in the context of epidemic situation is helpful to promote students' scientific learning better.

According to the CATLM (Moreno 2006, 2009), learners often need to invest and pay cognitive efforts in order to complete the learning task in the scientific learning supported by multimedia environment. Current research finds that negative emotions such as online social anxiety can decrease cognitive and behavioral engagement (Hwang et al. 2020). From the perspective of cognitive engagement, the theory of social psychology holds that positive emotions lead to heuristic processing strategies, while negative emotions lead to more systematic and analytical processing, making individuals pay more attention to the details of the environment (Bless 2000). Research on anxiety disorders has shown that negative emotions such as CA have negative effects on metacognition and fine processing strategies (Bridie and Sam 2008; Irak and Tosun 2008).

The effect of CA on behavioral engagement is controversial. According to the control-processing model, positive emotions can make the individual content with the status quo and give up the goal they are pursuing; on the contrary, negative emotions such as CA can make the individual think that they have not made enough progress in the goal task, thus leading to the extension and enhancement of learning investment (Carver and Scheier 1990). Considering the influence of emotion on learning behavior, Pekrun et al. (2002) found that negative high arousal emotions such as anxiety were related to low level of effort, indicating that anxiety may reduce learners' learning engagement. Branko (2001) also found that the stressful events college students experience will affect their learning burnout. However, the above statements are all aimed at general learning engagement, and lack of comparison from the comprehensive engagement, emotional engagement, behavior engagement and social engagement.

The current research mainly focused on the relationship between anxiety and cognitive, behavioral learning engagement, while the relationship between CA and scientific learning emotion, social engagement was relatively lacking. However, according to the Col model, the emotional atmosphere between social groups and members of learning communities was the key variable that affects learners' learning engagement (Akyol and Garrison 2011). Garrison et al. (1999) pointed that Col is able to use the atmosphere of social media to show real self in social and emotional aspects, this kind of community atmosphere was one of the reasons why learners are attracted to it. Therefore, this research will further 
inquiry the CA and scientific cognitive engagement (SCE), scientific emotional engagement (SEE), scientific behavioral engagement (SBE) and scientific social engagement (SSE), and further propose the following assumptions.

H3. CA is negatively correlated with SCE. H4. CA is negatively correlated with SEE. H5. CA is negatively correlated with SBE. H6. CA is negatively correlated with SSE.

\section{Research model}

According to the CATLM (Critcher and Ferguson 2011; Moreno 2006; Satpute et al. 2013), motivation theory (Bandura 1989) and model of Col (Garrison 2011), the present study proposed research hypotheses that indicated SSLA and SSLB played an antecedent role in predicting that CA would lead to SCE, SEE, SBE and SSE using the smart phone and the QODE model in COVID-19 pandemic. Consistent with this research proposition and the previous review, the present study proposed that self- efficacy of science learning will correlate with CA. In addition, CA will be associated with these sub- constructs of scientific engagement: SCE, SEE, SBE and SSE. Hence, the following research model (Fig.

1) was proposed:

\section{Research Design}

$A U$ Learn Science, a science-learning APP based on QODE inquiry learning model, was developed. The game design of this APP and research procedure were presented as follows.

\section{AU Learn Science game design based-on QODE model}

Pegg (2006) analyzed the existing scientific exploration models and classified them into POE, POCPE and PCMGE. POE is the most concise scientific learning model, consisting of prediction, observation,

and explanation. POCPE was an extension of POE, which complemented the data collection process. PCMGE was further modified on the basis of the two, adding two key steps of measurement and graph making. 
According to theory of Learning-by-doing (Lesgold 2001), doing with hands and brain was the tentacle of scientific exploration, which connected learners' thinking and objective world (Alvarez and Cerda 2003). However, the above three scientific learning models did not highlight the value of Doing. Therefore, based on the above model and learning by doing theory, the present study developed QODE model, which includes four steps of Question, Observation, Doing and Explanation. The first stage of Question means to pose the misunderstanding regarding to the current situation. Observation means that on the basis of a question, students use their senses to observe clues in the video directly according to a certain purpose, so as to get an understanding of the question. The critical stage of Doing refers to the realization of the course task by students' hands-on practice. Explanation is the elaboration of the mechanism and reasons in the previous course tasks. In the distance learning, Question firstly requires students to represent their doubts, Observation secondly requires students to observe phenomena and construct their own understanding of problems, Doing thirdly requires students to turn their understanding in their minds into hands-on practice, Explanation enables students to deepen and broaden their understanding of problems. Next, the role of the vaccine in Fig. 2 was taken as an example to explain specifically how the QODE is implemented.

Based on the QODE model, the developed science-learning APP was used to set up a learning

environment for learners. The design process of APP that explain the operation of QODE was presented in Fig. 2. Taking the role of the vaccine as an example: 1) Question: AU point the something confused like "can a vaccine be injected for a lifetime". 2) Observation: Watch carefully how human cells fight against viruses. 3) Doing: operate T-lymphocyte and B-lymphocyte to eliminate the virus by using hands.

4) Explanation: combine with human immune mechanism, the principle and mechanism about the timeliness of vaccine were explained. Through the 4-step QODE inquiry model, this APP supported students to learn science independently. WeChat, as a social software which also combined with $A U$ Learn Science and work together, was used by teachers to assist discuss, which played a key role in building communities.

Fig. 2 Design of $A U$ Learn Science APP

\section{Procedure}

The samples in the study came from a research project named technology supported scientific learning under coronavirus infection launched in Shandong Province, China from February to March 2020. The project aimed to implement the national call for No Suspension of Classes and provided science lesson for isolated students at home. Teachers and students who participated in the project completed two stages of learning and evaluation tasks after signing up voluntarily. In the first stage, the APP was 
downloaded by smart phone, and a total of 6 class hours ( 15 minutes per lesson) of one week were completed. In the second stage, in order to study the psychological state of students' learning under the influence of the epidemic situation, a unified learning evaluation test was conducted in the form of online after the completion of the course learning. The process of project implementation is shown in Fig. 3.

Fig. 3 Procedure of science learning project

\section{Participates}

382 students from grade 3 to grade 5 participated in the course, and 357 completed the questionnaire. Among them, $222(62.2 \%)$ were in grade three, $59(16.5 \%)$ in grade four and $76(21.3 \%)$ in grade five. There were 182 boys $(51 \%)$ and 175 girls $(49 \%)$; the average age was 9.7 years $(S D=1.0)$, and the age range was 8-12 years.

\section{Research Instruments}

First of all, based on combing the relevant questionnaires in previous studies, this study revised the questionnaire in combination with science learning situations. All the questionnaires were scored according to 5-Likert scales. Secondly, the reliability and validity of the revised questionnaire were analyzed, which proved to be reasonable and effective.

\section{Research questionnaire}

Measurement of scientific self-efficacy

The revised self-efficacy scale which developed by Yusong (2000) was used to measure Chinese students' scientific self-efficacy. The original scale was compiled by Pintrich and Groot (1990). In this study, it was revised in combination with scientific learning situations. The sample questions are as follows: I believe I have the ability to get good grades in science studies. The scale has a total of 16 questions, which are divided into two parts: SSLA and SSLB. The students' sense of scientific selfefficacy increased with the increase of their scores. 
Measurement of CA

CA scale was used to measure students' CA level. The original scale was compiled by Burton (1998). This study revised it in combination with scientific learning situations. The sample question is In the AU Learn Science game, I am worried that I would do wrong. There are 8 questions in the scale. The higher the score is, the higher the level of CA is.

Measurement of science learning engagement

In this study, the revised science learning engagement scale was used to evaluate the degree of students' engagement in scientific learning. The original scale was compiled by Wang et al. (2016). In this study, the scientific context was selected to revise the scale, and four dimensions of cognitive engagement, emotional engagement, behavioral engagement and social engagement were selected. The revised scale has 31 items in total. For example, I will do my science assignments carefully and make sure I do them correctly. The higher the score is, the stronger the individual's science learning engagement is.

\section{Reliability and validity analyses}

In the original questionnaire, there were 8 items for the SSLA, 8 items for the SSLB, 8 items for the CA, 8 items for SCE, 8 items for SEE, 8 items for SBE, and 7 items for the SCE dimension. According to confirmatory factor analysis, items that the indicator loading was below .7 were deleted (Chin 1988).

After cancelling the unreasonable items, revised questionnaire contained 8 items for SSLA, 8 items for SSLB, 8 items for CA, 7 items for SCE, 8 items for SEE, 7 items for SBE and 7 items for SCE. Next, the reliability and validity of the questionnaire were analyzed in the following steps.

First, the composite reliability (CR) could be used to evaluate the internal consistency of the questionaire (Fornell and Larcker 1981). As composite reliability values in this research ranged from .929 to .973, they all exceed the recommended threshold value of .7 (Hair et al. 2009; Nunnally 1978). Second, convergent validity in the present research was determined in order to ensure the (1) the average variance extracted (AVE) values were higher than .5 (Fornell and Larcker 1981) and (2) the factor loadings of each items were greater than .5 and significant (Nunnally 1978). In present study, AVE ranged from .653 to .819 and factor loadings ranged from .647 to .958 all the conditions are satisfied to show that the convergent validity is acceptable. Third, the independent $t$-test was used to explain the discriminative degree of each item. According to Himmerlfarb (1993) and Cureton (1957), the discriminative indicators of the items 
could be assessed by test the statistically significant difference between mean scores of people in the top $27 \%$ and mean scores of people in the bottom $27 \%$ of the subscale score distribution, and if the $t$-value is greater than $3\left(p<.001^{\star \star \star}\right)$, the discriminative power is significant (Green and Salkind 2004). The discriminative power was reasonable because the $t$-value of all items was from 19.314 to

97.190 which all larger than $3\left(p<.001^{\star \star \star}\right)$.

Forth, the Cronbach's a was used to evaluate internal consistency reliability of the questionnaire. According to Nunnally (1978), the internal reliability could be acceptable if the Cronbach's a value is large than .5. As shown in Table 1, the Cronbach's a for the whole questionnaire in present research was from .805 to .968 (all large than .5), indicating the reliability of the questionnaire was acceptable. Fifth, Byrne (2001) suggested that the construct validity of the questionnaire would be examined by using confirmatory factor analysis. Table 1 shows that the means of each construct ranged from 1.712 to 4.457 and the $S D$ were all below .942 , thereby indicating that the construct validity of instruments was reasonable.

\section{Common method bias test}

Harman single factor test was carried out on the research data. According to the standard of characteristic root greater than 1 , the results showed that 10 factors were extracted from unrotated factor analysis, and the variation of maximum factor variance interpretation was $33.19 \%$, less than the critical standard of $40 \%$ (Zhou and Long 2004), so there was no serious common method bias.

\section{Table 1}

Analyses of Mean, $S D$ and Cronbach's a.

\begin{tabular}{lllll} 
Constructs & Number of items & Mean & $S D$ & Cronbach's a \\
\hline Total & 53 & 3.906 & .597 & .805 \\
\hline SSLA & 8 & 4.206 & .886 & .961
\end{tabular}




\begin{tabular}{lllll} 
SSLB & 8 & 4.248 & .902 & .968 \\
\hline CA & 8 & 1.712 & .942 & .952 \\
\hline SCE & 7 & 4.178 & .857 & .912 \\
\hline SEE & 8 & 4.323 & .868 & .939 \\
\hline SBE & 7 & 4.457 & .854 & .946 \\
\hline SSE & 7 & 4.215 & .844 & .912
\end{tabular}

\section{Research Results}

PLS-SEM method has unique advantages in analyzing small sample sizes and non-normal data, and it can also be used in exploration research objectives and ensuring conversion (Hair et al. 2012; Ringle et al. 2012), therefore PLS-SEM method was used in this study. The software of SPSS 20.0 and Smart-PLS

2.0 was used to analyze the collected data. First, we used the Pearson's $r$ coefficient to estimate degree of linear correlation among SSLA, SSLB, CA, SCE, SEE, SBE and SSE. Second, the method of bootstrapping was used to estimate the sampling distribution and the path coefficients, so that the measurement and structural models was examined. Finally, the analysis of R2 was used to measure the explanatory power of the model.

\section{Correlation analyses}

The results of Pearson's correlation analyses are showed in Table 2. In the correlation matrix, after controlling for variables of gender and age, there were significant correlations among SSLA, SSLB, CA, SCE, SEE, SBE and SSE. There was a significant positive correlation among SSLA, SSLB, SCE, SEE, SBE and SSE, while CA was negatively correlated with other constructs. The correlative degree between SSLA and SSLB was largest $(r=.911)$, however, the correlative degree between SSLA and CA was least $(r=$ -.605). All the coefficients were large, indicating that all the dimensions were highly relevant.

\section{Table 2}

The correlation matrix. 


\begin{tabular}{llllllll} 
& SSLA & SSLB & SCE & SEE & SBE & SSE & CA \\
\hline SSLA & 1 & & & & & & \\
\hline SSLB & $.911^{\star \star}$ & 1 & & & & & \\
\hline SCE & $.767^{\star \star}$ & $.813^{\star \star}$ & 1 & & & & \\
\hline SEE & $.793^{\star \star}$ & $.816^{\star \star}$ & $.853^{\star \star}$ & 1 & & & \\
\hline SBE & $.777^{\star \star}$ & $.806^{\star \star}$ & $.830^{\star \star}$ & $.909 \star \star$ & 1 & & \\
\hline SSE & $.807^{\star \star}$ & $.843^{\star \star}$ & $.826^{\star \star}$ & $.852^{\star \star}$ & $.860^{\star \star}$ & 1 & \\
\hline CA & $-.605^{\star \star}$ & $-.618^{\star \star}$ & $-.726^{\star \star}$ & $-.713^{\star \star}$ & $-.745^{\star \star}$ & $-.714^{\star \star}$ & 1 \\
& & & & & & & \\
& & & & & & &
\end{tabular}

\section{Structural model analysis}

After analyzing the correlation among variables and reliability and validity of model, the explanatory

and predictive power of model was estimated. Table 3 and Figure 4 showed the supported results of the hypothesis. First, CA had a direct significant negative correlation with SCE, SEE, SBE and SSE ( $\beta=-.729$, $\left.t=17.058^{\star \star \star} ; \beta=-.715, t=16.702^{\star \star \star} ; \beta=-.752, t=20.108^{\star \star \star} ; \beta=-.728, t=17.282^{\star \star \star}\right)$. Furthermore, SSLA and SSLB had direct significant negative correlations with $C A(\beta=-.334, t=2.652 \star * ; \beta=-.312, t=2.429 *)$. In addition, according to the results of $R 2$, the explained variance of the SSLA and SSLB on CA was 39.6\%, the explained variance of the CA on SCE was $53.1 \%$; the explained variance of CA on SEE was $50.9 \%$; the explained variance of the CA on SBE was $56.4 \%$; the explained variance of the CA on SSE was $52.8 \%$. In conclusion, it could be determined that the independent variables had great reliability in the prediction and interpretation of dependent variables.

\section{Table 3}

Path coefficient $\beta, t$-statistic, $R 2$ of the PLS measurement model. 


\begin{tabular}{lllll} 
Path & Path coefficient $\beta$ & $t$-statistic & Construct & $R 2$ \\
\hline $\mathrm{CA} \rightarrow \mathrm{SCE}$ & -.729 & $17.058^{\star \star \star}$ & & \\
\hline $\mathrm{CA} \rightarrow \mathrm{SEE}$ & -.715 & $16.702^{\star \star \star}$ & $\mathrm{CA}$ & .396 \\
\hline $\mathrm{CA} \rightarrow \mathrm{SBE}$ & -.752 & $20.108^{\star \star \star}$ & $\mathrm{SCE}$ & .531 \\
\hline $\mathrm{CA} \rightarrow \mathrm{SSE}$ & -.728 & $17.282^{\star \star \star}$ & $\mathrm{SEE}$ & .509 \\
\hline $\mathrm{SSLA} \rightarrow \mathrm{CA}$ & -.334 & $2.652^{\star \star}$ & $\mathrm{SBE}$ & .564 \\
\hline $\mathrm{SSLB} \rightarrow \mathrm{CA}$ & -.312 & $2.429^{\star}$ & $\mathrm{SSE}$ & .528
\end{tabular}

$\star \star \star p<.001,{ }^{\star *} p<.01,{ }^{\star} p<.05$

\section{Discussion}

The present study designed a QODE model in the APP called AU Learn Science for elementary school students to learn science during COVID-19 pandemic. The APP integrating QODE model provided an opportunity for students to enhance learning engagement, and also revealed the effects of scientific selfefficacy and CA on science engagement.

The results supported by the data were consistent with the initial research hypothesis, indicating that the theoretical hypothesis including $\mathrm{H} 1, \mathrm{H} 2, \mathrm{H} 3, \mathrm{H} 4, \mathrm{H} 5$ and $\mathrm{H} 6$ were all verified. From the view of Bandura's Motivation Theory (Bandura 1989), Self-efficacy refers to an individual's subjective

perception or belief in the ability to effectively control that can result in long-lasting engagement for a certain learning topic. This research designed the QODE model by applying science learning APP, which was expected to have a motivational impact on science learning engagement in the cognitive, emotional, behavioral and social dimensions. Follow the CATLM, positive or negative emotion factors play an intermediary role in the learning process by increasing or decreasing cognitive engagement (Moreno 2006 , 2009). CA, as a cognitive component of anxiety (Ingram and Kendall 1987), weakens the role of self-efficacy and learning engagement.

In examining hypothesis of $\mathrm{H} 1$ and $\mathrm{H} 2$, the results of this research indicated that SSLA and SSLB was negatively correlated to $\mathrm{CA}$ after controlling for demographic variables. The result is supported by Singh, Bhadauria, Jain and Gurung (2013), who pointed out that increasing the level of anxiety would decrease 
the level of self-efficacy in learning with media. Junfeng et al. (2020) pointed out that COVID-19 pandemic led to a sharp rise in the prevalence of anxiety in China. As the source and mechanism of COVID-19 are not clear, it aggravates people's CA in the epidemic situation, which will affect students' distance learning process. From a cognitive-affective perspective, self-efficacy belongs to self-concept, which is related to CA as a part of state anxiety (Morony et al. 2013). Affected by the epidemic situation, on the one hand, students' anxiety level increases, which will damage the normal sense of scientific learning efficacy. On the other hand, the enhancement of scientific learning efficacy may help to reduce students' CA (Hong et al. 2017). This result is consistent with the assertion of Morris et al. (1981) and Tanaka et al. (2006), advocating that anxiety is a tensional situation variables or transient experience of worry. Therefore, appropriate teaching and psychological guidance should be carried out to improve students' self-efficacy, so as to reduce students' CA.

In examining hypothesis of $\mathrm{H} 3, \mathrm{H} 4, \mathrm{H} 5$ and $\mathrm{H} 6$, the results of this research indicated that $\mathrm{CA}$ was

negatively correlated to four types of learning engagement including SCE, SEE, SBE and SSE. The current results are consistent with the previous studies (Pekrun et al. 2002). First of all, from the perspective of cognitive engagement, negative emotions will make individuals pay more attention to their surroundings and lose their attention to cognitive goals (Pintrich 2003). The negative emotions such as anxiety caused by the epidemic may damage the mediating effect of cognitive engagement on learning engagement (Shu-Yun Sophie 2013). Second, from the perspective of social engagement, the theory of Col point that only through the interaction of cognitive presence, social presence and teaching presence, learning could occur within the Community (Shea and Bidjerano 2009). Social existence creates a purposeful online inquiry learning environment in which learners' thoughts and ideas can be connected with each other (Shea and Bidjerano 2009). However, CA weakens the beneficial connection between social communication and learning engagement (Brom et al. 2014), this result is consistent with the research from Scanlon et al. (2020). Third, from the perspective of emotional engagement, the epidemic split the function of campus as a community and emotional engagement became an isolated part ignored by educators in distance learning. Social presence includes three categories: emotional expression, open

communication and group cohesion, which emphasizes the role of social factors in learning engagement. Among them, emotional expression attaches importance to students' emotional response and interactive response (Rourke et al. 2007). From this aspect, CA also weakens the role of emotional engagement response and interactive response in emotional expression. Fourth, from the perspective of behavioral engagement, the research found that when students use APP for distance learning, Col could promote their behavioral engagement and motivation structure (Shea and Bidjerano 2010), this shows that CA played a negative role. To sum up, our study built a learning community for students to communicate with each other through the combination of $A U$ Learn Science APP and social media called WeChat. At the same time, teachers are also able to guide students through WeChat and other social media, jointly 
played the role of online learning community in promoting learning engagement (Shea and Bidjerano 2009).

\section{Conclusion}

Integrating the CATLM, Bandura's Motivation Theory and theory of Col, learning engagement is positively affected by students' self-efficacy and negatively affected by students' CA. The present research confirmed that self-efficacy was a strong and direct determinant of student's learning engagement to practice the QODE application. It further proved that student's learning engagement using distance learning derived a mixture of self-efficacy from CA via Col.

\section{The contributions of theory and practice}

To sum up, our research suggested two-part contributions both in theory and practice. From the perspective of theory, structural equation modeling is helpful to allow us to predict experimental outcomes. First, it was found that the learning engagement of using intelligent devices comes from the self-efficacy in the process of distance learning. Second, the study discovered an in-depth relationship between science learning engagement comprised by SCE, SEE, SBE and SSE and self-efficacy comprised by SSLA and SSLB where prior research was limited to general dimensions of variables. Third, a more intensive understanding of CA in the long-distance online environment was enhanced. Forth, the inquiry model of QODE, as a promising distance learning method, was constructed based on the prior learning theory which played the crucial theoretical guidance during epidemic of COVID-19. From the view of practice, the AU Learn Science APP was developed to promote and support student's science learning during COVID-19 epidemic. Using the QODE to integrate the Col, student's science engagement could be cultivated. And all the contributions are expected to set an effective example for other countries that are fighting against the COVID-19.

\section{Future study}

Although some research findings and achievements have been made in this study, there are still some deficiencies. First, this study is a cross-sectional study, without the control group and the experimental group of comparative study, unable to get the strict sense of causality. Second, using the method of selfreport questionnaire data collection, there is a certain error in the subjectivity of the answer. However, by 
using the method of structural equation modeling, it also provides a reliable support for the research hypothesis, and can have an enlightenment on the similar research on distance learning in the follow-up research.

In the future research, experimental design can be used to further determine the causal relationship and internal mechanism between variables, and to explore the change of students' learning with the development of the epidemic situation through tracking research. What's more, in order to help students overcome the adverse effects of the epidemic on students, it may be a new way to study the science learning engagement of distance learning from the perspective of psychological flexibility. A recent study about the effect of mental resilience on learning engagement (Zhongze et al. 2016) suggests a mental resilience in response to stress status could further be used to examine the moderating effect between anxiety and engagement. In addition, regarding the educational diversity in Chinese different regions (Xiantong et al. 2019), it is also worth carrying out follow-up work to verify the effect of APP in different cultural backgrounds. Therefore, in the post epidemic era, improving mental resilience will help students from different regions cope with the anxiety brought by negative life events, and then make all the students' learning engagement develop in a positive direction.

\section{Declarations}

Funding Information Without funding support

\section{Compliance with Ethical Standards}

Conflict of Interest The author declares that there is no conflict of interest.

Ethical and Consent Statements All human trials meet the ethical standards of the Chinese Association for Ethical Research (CAES). The informed consent of all participants participating in the study is obtained in accordance with CAES regulations.

\section{References}

Akyol, Z., \& Garrison, D. R. (2011). Assessing metacognition in an online community of inquiry. The Internet and Higher Education, 14(3): 183-190.

Alvarez, F., \& Cerda, E. (2003). Learning by doing in a T-period production planning: analytical solution. European Journal of Operational Research, 150(2), 353-369. 
Amanda J, R., Jillian, W., Mervyn, W., \& Deanna, N. (2016). The predictive relationship among the community of inquiry framework, perceived learning and online, and graduate students' course grades in online synchronous and asynchronous courses. International Review of Research in Open \& Distance Learning, 17(3), 18-35.

Bandura, A. (1982). Self-efficacy mechanism in human agency. American Psychologist, 37(2), 122- 147.

Bandura, A. (1989). Regulation of cognitive processes through perceived self-efficacy. Developmental Psychology, 25(5), 729-735.

Bandura, A. (1993). Perceived self-efficacy in cognitive development and functioning. Educational Psychologist, 28(2), 117-148.

Bandura, A., \& Schunk, D. H. (1981). Cultivating competence, self-efficacy, and intrinsic interest through proximal self-motivation. Journal of Personality \& Social Psychology, 41(3), 586-598.

Bauer, \& Julius. (1965). Definition(s) of anxiety. The Journal of the American Medical Association, 191(5), 420.

Bless, H. (2000). The interplay of affect and cognition: The mediating role of general knowledge structures. In J. Forgas (Ed.), Feeling and thinking: The role of affect in social cognition (pp. 201-222). New York: Cambridge University Press.

Branko, S. (2001). The syndrome of burnout, self-image, and anxiety with grammar school students. Horizons of Psychology, 10(2): 21-32.

Brígido, M., Borrachero, A. B., Bermejo, M. L., \& Mellado, V. (2013). Prospective primary teachers' selfefficacy and emotions in science teaching. European Journal of Teacher Education, 36(2), 200-217.

Britner, S. L., \& Pajares, F. (2006). Sources of science self-efficacy beliefs of middle school students. Journal of Research in Science Teaching, 43(5), 485-499.

Brom, C., Buchtova, M., Sisler, V., Dechterenko, F., Palme, R., \& Glenk, L. M. (2014). Flow, social interaction anxiety and salivary cortisol responses in serious games: a quasi-experimental study. Computers \& Education, 79(oct.), 69-100.

Burton, D. (1998). Measuring competitive state anxiety. In J. L. Duda (Ed.), Advances in sport and exercise psychology measurement (pp. 129-148). Morgantown: Fitness Information Technology, Inc.

Bybee, R., Taylor, J.A., Gardner, A., van Scotter, P., Carlson, J., Westbrook, A., et al. (2006). The BSCS $5 E$ instructional model: Origins and effectiveness. BSCS, Colorado Springs, CO. 
Byrne, B. M. (2001). Structural equation modeling with AMOS, EQS, and LISREL: comparative approaches to testing for the factorial validity of a measuring instrument. International Journal of Testing, 1(1), 5586 .

Carver, C. S., \& Scheier, M. F. (1990). Origins and functions of positive and negative affect: a controlprocess view. Psychological Review, 97(1), 19-35.

Chen, Y. (2019). Effect of Mobile Augmented Reality on Learning Performance, Motivation, and Math Anxiety in a Math Course. Journal of Educational Computing Research, 0(0), 1-28.

Chin, W.W. (1998). The Partial Least Squares Approach to Structural Equation Modeling. Modern Methods for Business Research, 295, 295-336.

Christenson, S. L., Reschly, A. L., \& Wylie, C. (2012). A Self-determination Theory perspective on student engagement. In Johnmarshall Reeve. Handbook of Research on Student Engagement (pp. 149-172). US: Springer.

Critcher, C. R., \& Ferguson, M. J. (2011). Affect in the abstract: abstract mindsets promote sensitivity to affect. Journal of Experimental Social Psychology, 47(6), 1185-1191.

Cureton, E. E. (1957). The upper and lower twenty-seven per cent rule. Psychometrika, 22, 293-296.

Edelson, D., Gordin, D., et al. (1999). Addressing the challenges of inquiry-based learning through technology and curriculum design. Journal of the Learning Sciences, 8(3-4): 391-450.

Finn, J. D., \& Zimmer, K. (2012). Student engagement: What is it and why does it matter? In S. Christenson, A. L. Reschy, \& C. Wylie (Eds.), Handbook of Research on Student Engagement (pp. 97-131). New York: Springer.

Floyd, E. M., William, E. S., Charles, R. C., Shigekazu, T., \& Atsushi, Y. (1992). A study of the logical thinking skills and integrated process skills of junior high school students in north carolina and japan. Science Education, 76(2), 211-222.

Fornell, C., \& Larcker, D. F. (1981). Structural equation models with unobservable variables and measurement error. Journal of Marketing Research, 18(1), 39-50.

Fredricks, J. A., \& Paris, B. A. H. (2004). School engagement: potential of the concept, state of the evidence. Review of Educational Research, 74(1), 59-109.

Fredricks, J. A., Wang, M. T., Schall Linn, J., Hofkens, T. L., Sung, H., \& Parr, A., et al. (2016). Using qualitative methods to develop a survey measure of math and science engagement. Learning \& Instruction, 43, 5- 15. 
Gallagher, B., \& Cartwright-Hatton, S. (2008). The relationship between parenting factors and trait anxiety: Mediating role of cognitive errors and metacognition. Journal of Anxiety Disorders, 22(4), 722-733.

Gardner, C. M. (2011). Supporting cognitive engagement in a learning-by-doing learning environment: Case studies of participant engagement and social configurations in Kitchen Science Investigators. Georgia Institute of Technology.

Garrison, D. R. (2011). E-learning in the 21st century: A framework for research and practice.

Cambridge: Taylor \& Francis.

Garrison, D. R., \& Akyol (2015). Toward the development of a metacognition construct for communities of inquiry. The Internet and Higher Education, (24): 66-71.

Garrison, D. R., Anderson, T., \& Archer, W. (1999). Critical inquiry in a text-based environment: computer conferencing in higher education. Internet \& Higher Education, 2(2-3), 87-105.

Garrison, D. R., Anderson, T., \& Archer, W. (2001). Critical thinking, cognitive presence, and computer conferencing in distance education. American Journal of Distance Education, 15(1), 7-23.

Gibson, S., \& Dembo, M. H. (1984). Teacher efficacy: a construct validation. Journal of Educational Psychology, 76(4), 569-582.

Green, S. B., \& Salkind, N. (2004). Using SPSS for Windows and Macintosh: Analyzing and understanding data (4th ed.). Englewood Cliffs, NJ: Prentice-Hall.

Hair, J. F., Black, W. C., Babin, B. J., \& Anderson, R. E. (2009). Multivariate data analysis (7th ed.).

Upper Saddle River, NJ: Pearson Prentice Hall.

Hair, J. F., Sarstedt, M., Ringle, C. M., \& Mena, J. A. (2012). An assessment of the use of partial least squares structural equation modeling in marketing research. Journal of the Academy of Marketing Science, 40(3), 414-433.

Himmerlfarb, S. (1993). The measurement of attitudes. In A. H. Eagly, \& S. Chaiken (Eds.), The Psychology of Attitudes. Orlando, FL: Harcourt Brace Jovanovich, Inc.

Holstermann, N., Grube, D., \& Boegeholz, S. (2009). The influence of emotion on students' performance in dissection exercises. Journal of Biological Education, 43(4), 164-168.

Hong, J.C., Hwang, M.Y., Liu, M.C., Ho, H.Y., \& Chen, Y.L. (2014). Using a "prediction-observationexplanation" inquiry model to enhance student interest and intention to continue science learning predicted by their internet cognitive failure. Computers \& Education, 72, 110-120. 
Hong, J.-C., Hwang, M.-Y., Tai, K.-H., \& Tsai, C.-R. (2017). An Exploration of Students' Science Learning Interest Related to Their Cognitive Anxiety, Cognitive Load, Self-Confidence and Learning Progress Using Inquiry-Based Learning With an iPad. Research in Science Education, 47(6), 1193-1212.

Hordacre, B., Immink, M. A., Ridding, M. C., \& Hillier, S. (2016). Perceptual-motor learning benefits from increased stress and anxiety. Human Movement Science, 49, 36-46.

Hwang, M.Y., Hong, J.C., Tai, K.H., Chen, J.T., \& Gouldthorp, T. (2020). The relationship between the online social anxiety, perceived information overload and fatigue, and job engagement of civil servant LINE users. Government Information Quarterly, 37(1), 1-8.

Ingram, R. E., \& Kendall, P. C. (1987). The cognitive side of anxiety. Cognitive Therapy \& Research, 11(5), 523-536.

Irak, M., \& Tosun, A. (2008). Exploring the role of metacognition in obsessive-compulsive and anxiety symptoms. Journal of Anxiety Disorders, 22(8), 1316-1325.

Johnson, M. L., \& Sinatra, G. M. (2013). Use of task-value instructional inductions for facilitating engagement and conceptual change. Contemporary Educational Psychology, 38(1), 51-63.

Jrvel, S., Veermans, M., \& Leinonen, P. (2008). Investigating student engagement in computer- supported inquiry: a process-oriented analysis. Social Psychology of Education, 11(3), 299-322.

Junfeng, L., Zhiyun, Y., Hui, Q., Yu. W., Lingyu, J., Junjun, Ji., \& Kefeng, L. (2020). Anxiety and depression among general population in China at the peak of the COVID-19 epidemic. World Psychiatry, 19(2),49-250.

Kairong, W., Tao, X., \& Qiong, L. (1999). A Study on the Relationship between self-efficacy attribution and Academic Performance of Middle school Students [in Chinese]. Psychological Development and Education, (4), 22-25.

Kanuka, H. \& Anderson, T. (1998) Online social interchange, discord, and knowledge construction. Journal of Distance Education, 13(1). Retrieved from http:// cade.athabascau.ca/vol13.1/kanuka.html.

Khng, \& Hui, K. (2016). A better state-of-mind: deep breathing reduces state anxiety and enhances test performance through regulating test cognitions in children. Cognition and Emotion, 1-9.

Kizilbash, A. H., Vanderploeg, R. D., \& Curtiss, G. (2002). The effects of depression and anxiety on memory performance. Archives of Clinical Neuropsychology, 17(1), 57-67.

Lam, C. C., Wong, N. Y., \& Wong, K. M. P. (1999). Students' conception of mathematics learning: a Hong Kong study. Curriculum and Teaching, 14(2), 27- 48. 
Lesgold, A.M. (2001). The nature and methods of learning by doing. American Psychologist, 56(11), 964973.

Liu, R. D., Zhen, R., Ding, Y., Liu, Y., Wang, J., \& Jiang, R., et al. (2017). Teacher support and math engagement: roles of academic self-efficacy and positive emotions. Educational Psychology, 1-14.

Lynn, S. L. (2000). Map use and the development of spatial cognition: seeing the bigger picture.

Developmental Science, 3(3), 270-274.

Lynn, S. L., Kim, A. K., \& Adam, E. C. (2011). Spatial foundations of science education: the illustrative case of instruction on introductory geological concepts. Cognition and Instruction, 29(1), 45-87.

Martens, R., Burton, D., Vealey, R. S., Bump, L. A., \& Smith, D. E. (1990). Development and validation of the Competitive State Anxiety Inventory-2 (CSAI-2). In R. Martens, R. S. Vealey, \&

1. Burton (Eds.), Competitive anxiety in sport (pp. 117-213). Champaign: Human Kinetics Publishers, Inc.

Martin, A.J. (2008). How domain specific is motivation and engagement across school, sport, and music? A substantive-methodological synergy assessing young sportspeople and musicians. Contemporary Educational Psychology, 33(4), 785-813.

Mcconney, A., Oliver, M. C., Woods-Mcconney, A., Schibeci, R., \& Maor, D. (2014). Inquiry, engagement, and literacy in science: a retrospective, cross-national analysis using PISA 2006. Science Education, 98(6), 963-980.

Ministry of Education. (2020, April 13). Video conference on HEls online education held in Beijing.

Retrieved from http://en.moe.gov.cn/news/press_releases/202004/t20200420_444988.html Ministry of Education. (2020, March 06). The Ministry of education has deployed to do a good job in

the work of "no suspension of classes" in primary and secondary schools. Retrieved from http://www.moe.gov.cn/jyb_xwfb/gzdt_gzdt/s5987/202003/t20200306_428342.html

Moreno, R. (2006). Does the modality principle hold for different media? A test of the method-affectslearning hypothesis. Journal of Computer Assisted Learning, 22(3), 149-158.

Moreno, R. (2009). Learning from animated classroom exemplars: the case for guiding student teachers' observations with metacognitive prompts. Journal of Educational Research and Evaluation, 15, 487-501.

Morony, S., Kleitman, S., Lee, Y. P., \& Stankov, L. (2013). Predicting achievement: confidence vs. selfefficacy, anxiety, and self-concept in Confucian and European countries. International Journal of 
Educational Research, 58, 79-96.

Morris, L. W., Davis, M. A., \& Hutchings, C. H. (1981). Cognitive and emotional components of anxiety: literature review and a revised worry-emotionality scale. Journal of Educational Psychology, 73, 541555 .

Neng, L., Shaohui, L., Nan, Y., Yunhua, P., Yumei, W., \& Jie, T., et al. (2018). Correlations among psychological resilience, self-efficacy, and negative emotion in acute myocardial infarction patients after percutaneous coronary intervention. Frontiers in Psychiatry, 9: 1.

Nunnally, J. (1978). Psychometric theory. New York: McGraw-Hill.

Papert, S. (1980). Mindstorms: Children, computers, and powerful ideas. New York, NY, Basic Books. Pedaste, M., Mäeots, M., Siiman, L.A., de Jong, T., van Riesen, S.A.N., \& Kamp, E.T., et al. (2015).

Phases of inquiry-based learning: definitions and the inquiry cycle. Educational Research Review, 14, 4761.

Pegg, J. M. (2006). Developing explanations: student reasoning about science concepts during claimsevidence inquiry lessons. Ph.D. diss. Corvallis, OR: Department of Science and Math Education, Oregon State University.

Pekrun, R., Goetz, T., Titz, W., \& Perry, R. P. (2002). Academic emotions in students' self-regulated learning and achievement: a program of qualitative and quantitative research. Educational Psychologist, 37(2), 91-105.

Pintrich, P. R. (2003). A motivational science perspective on the role of student motivation in learning and teaching contexts. Journal of Educational Psychology, 95(4), 667-686.

Pintrich, P. R., \& De Groot, E. V. (1990). Motivational and self-regulated learning components of classroom academic performance. Journal of Educational Psychology, 82(1), 33-40.

Ramirez, G., Chang, H., Maloney, E. A., Levine, S. C., \& Beilock, S. L. (2016). On the relationship between math anxiety and math achievement in early elementary school: The role of problem solving strategies. Journal of Experimental Child Psychology, 141, 83-100.

Remesal, A., \& Friesen, N. (2014). Inquiry into 'communities of inquiry': Knowledge, communication, presence, community. E-Learning and Digital Media, 11(1): 1-4.

Rimm-kaufman, S. E., Baroody, A. E., Larsen, R. A. A., Curby, T. W., \& Abry, T. (2014). To what extent do teacher-student inter- action quality and student gender contribute to fifth graders' engagement in mathematics learning. Journal of Educational Psychology, 107(1), 170-185. 
Ringle, C. M., Sarstedt, M., \& Straub, D. W. (2012). A critical look at the use of PLS-SEM in MIS quarterly. MIS Quarterly, 36(1), 3-14.

Rourke, L., Anderson, T., \& Garrison, D. R. (2007). Assessing social presence in asynchronous text- based computer conferencing. International Journal of E-Learning \& Distance Education, 14(2): 50-71.

Samantha Kelly, B., Rebecca, D., Richard, A., Gideon James, R., \& Neil, Greenberg. (2018). A systematic, thematic review of social and occupational factors associated with psychological outcomes in healthcare employees during an infectious disease outbreak. Journal of Occupational and Environmental Medicine, 60(3), 248-257.

Satpute, A. B., Shu, J., Weber, J., Roy, M., \& Ochsner, K. N. (2013). The functional neural architecture of self-reports of affective experience. Biological Psychiatry, 73(7), 631-638.

Scanlon, C. L., Toro, J. D., \& Wang, M.T. (2020). Socially Anxious Science Achievers: The Roles of Peer Social Support and Social Engagement in the Relation Between Adolescents' Social Anxiety and Science Achievement. Journal of Youth and Adolescence, 49(5), 1005-1016.

Schaufeli, W. B., Salanova, M., Vicente González-romá, \& Bakker, A. B. (2002). The measurement of engagement and burnout: a two sample confirmatory factor analytic approach. Journal of Happiness Studies, 3(1), 71-92.

Selcan, K., \& Zahide, Y. (2018). Investigation of community of inquiry framework in regard to selfregulation, metacognition and motivation. Computers \& Education, 126, 53-64.

Selcuk, O, \& Sukriye, B. O. (2020, May). Levels and predictors of anxiety, depression and health anxiety during COVID-19 pandemic in Turkish society: The importance of gender. International Journal of Social Psychiatry. Retrieved from https://journals.sagepub.com/doi/pdf/10.1177/0020764020927051

Seyle, H. (1950). The physiology and pathology of exposure to stress, Acta, Montreal, Canada.

Seyle, H. (1952). Story of the adaptation syndrome, Acta, Montreal, Canada. Seyle, H. (1956). Stress of life. McGrawwhill Co. New York.

Shea, P., \& Bidjerano, T. (2009). Community of inquiry as a theoretical framework to foster "epistemic engagement" and "cognitive presence" in online education. Computers \& Education, 52(3), 543- 553.

Shea, P., \& Bidjerano, T. (2010). Learning presence: towards a theory of self-efficacy, self-regulation, and the development of a communities of inquiry in online and blended learning environments. Computers \& Education, 55(4), 1721-1731. 
Shu-Yun Sophie, C. (2013). An empirical investigation of the effectiveness of project-based course learning within hospitality programs: the mediating role of cognitive engagement. Journal of Hospitality Leisure Sport \& Tourism Education, 13, 213-225.

Singh, A., Bhadauria, V., Jain, A., \& Gurung, A. (2013). Role of gender, self-efficacy, anxiety and testing formats in learning spreadsheets. Computers in Human Behavior, 29(3), 739-746.

Skinner, E. A., Kindermann, T. A., \& Furrer, C. J. (2009). A motivational perspective on engagement and disaffection: conceptualization and assessment of children's behavioral and emotional participation in academic activities in the classroom. Educational and Psychological Measurement, 69(3), 493-525.

Soltanlou, M., Artemenko, C., Dresler, T., Fallgatter, A. J., Ehlis, A. C., \& Nuerk, H. C. (2019). Math anxiety in combination with low visuospatial memory impairs math learning in children. Frontiers in Psychology, 10.

Spielberger, C. (1972). Anxiety as an emotional state. In C. D. Spielberger (Ed.), Anxiety: current trends in theory and research (Vol. 1, pp. 23-49). New York: Academic.

Tanaka, A., Takehara, T., \& Yamauchi, H. (2006). Achievement goals in a presentation task: performance expectancy, achievement goals, state anxiety, and task performance. Learning and Individual Differences, 16(2), 93-99.

Taylor, L. M., Casto, D. J., \& Walls, R. T. (2004). Tools, time, and strategies for integrating technology across the curriculum. Journal of Constructivist Psychology, 17(2), 121-136.

UNESCO. (2020, April 30). New guidelines provide roadmap for safe reopening of schools. Retrieved from https://en.unesco.org/news/new-guidelines-provide-roadmap-safe-reopening-schools

Valentiner, D.P., Telch, M.J., Petruzzi, D.C., \& Bolte, M.C. (1996). Cognitive mechanisms in claustrophobia: an examination of reiss and mcnally's expectancy model and bandura's self- efficacy theory. Cognitive Therapy \& Research, 20(6), 593-612.

Wang, M. T., Fredricks, J. A., Ye, F., Hofkens, T. L., \& Linn, J. S. (2016). The math and science engagement scales: scale development, validation, and psychometric properties. Learning \& Instruction, 43, 16-26.

Weinberg, R. S., \& Gould, D. (2003). Foundations of sport and exercise psychology (3rd ed.).

Champaign: Human Kinetics Publishers, Inc.

White, B. Y., \& Frederiksen, J. R. (1998). Inquiry, modeling, and metacognition: making science accessible to all students. Cognition and Instruction, 16(1), 3-118.

WHO. (2020, June 1). WHO Coronavirus Disease (COVID-19) Dashboard. Retrieved from https://covid19.who.int/ 
Xiantong, Y, Mengmeng, Z, Xin, S, Lan, H, \& Qiang, W. (2019). Reginal Educational Equity: A Survey on the Ability to Design Scientific Experiments of Sixth-grade Students. Journal of Baltic Science Education, 18(6), 971-985.

Yeh, Y.C., Yen, C.F., Lai, C.S., Huang, C.H., Liu, K.M., \& Huang. I.T. (2007). Correlations between academic achievement and anxiety and depression in medical students experiencing integrated curriculum reform. Kaohsiung Journal of Medical Sciences, 23(8), 379-386.

Yusong, L. (2000). Study on achievement goals, attribution styles and academic self-efficacy of college students. (Unpublished master's thesis). Central China Normal University, Wuhan.

Zhen, R., Liu, R. D., Ding, Y., Wang, J., Liu, Y., \& Xu, L. (2017). The mediating roles of academic self-efficacy and academic emotions in the relation between basic psychological needs satisfaction and learning engagement among Chinese adolescent students. Learning and Individual Differences, 54, 210216.

Zhen, R., Liu, R.-D., Ding, Y., Liu, Y., Wang, J., \& Xu, L. (2016). The moderating role of intrinsic value in the relation between psychological needs support and academic engagement in mathematics among Chinese adolescent students. International Journal of Psychology, 53(4), 313-320.

Zhongze, Y., Mingyue, S., \& Tengfei, Liang. (2016). The influence of stress life events on college students' study engagement: the moderate effect of mental resilience. China Journal of Health Psychology, 24(4), 618-621.

Zhou, H., and Long, L. (2004). Statistical remedies for common method biases [in Chinese]. Advances in Psychological Science, 12, 942-950.

Zhu, E. (2006). Interaction and cognitive engagement: an analysis of four asynchronous online discussions. Instructional Science, 34(6), 451-480.

\section{Figures}




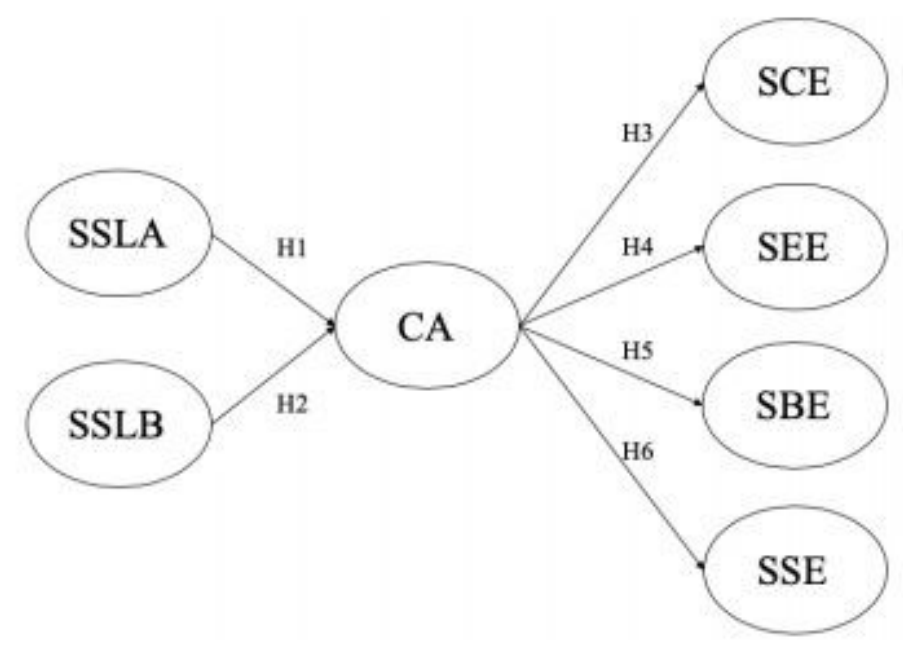

Figure 1

Research model
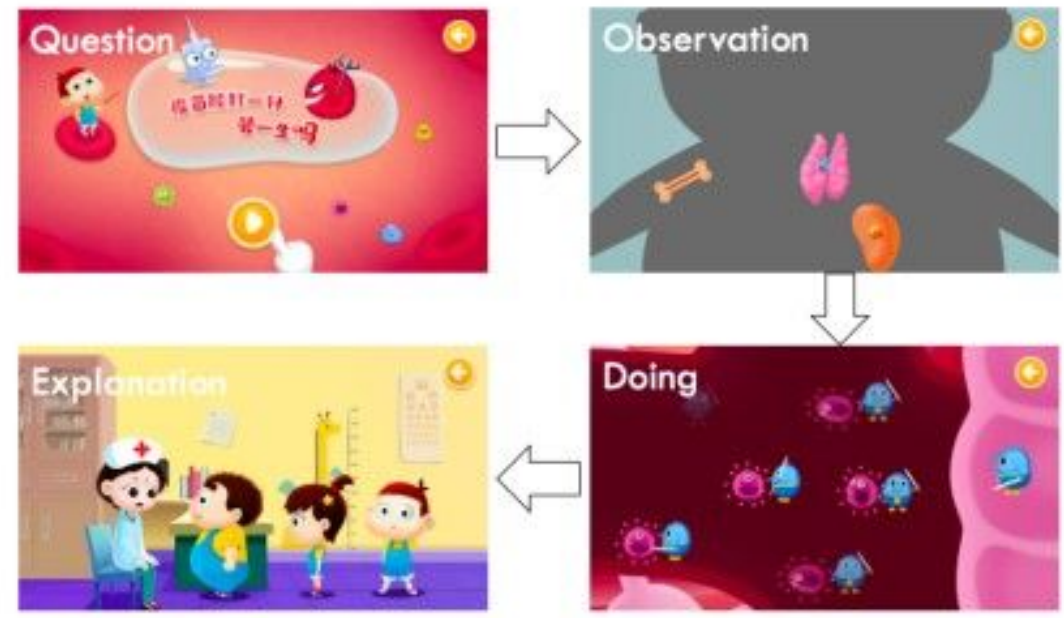

\section{Figure 2}

\section{Design of AU Learn Science APP}

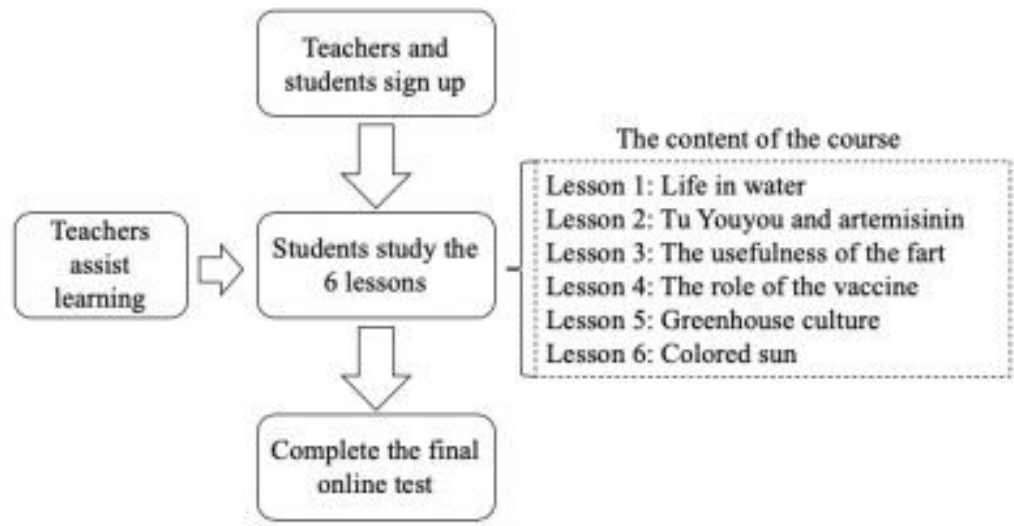


Figure 3

Procedure of science learning project

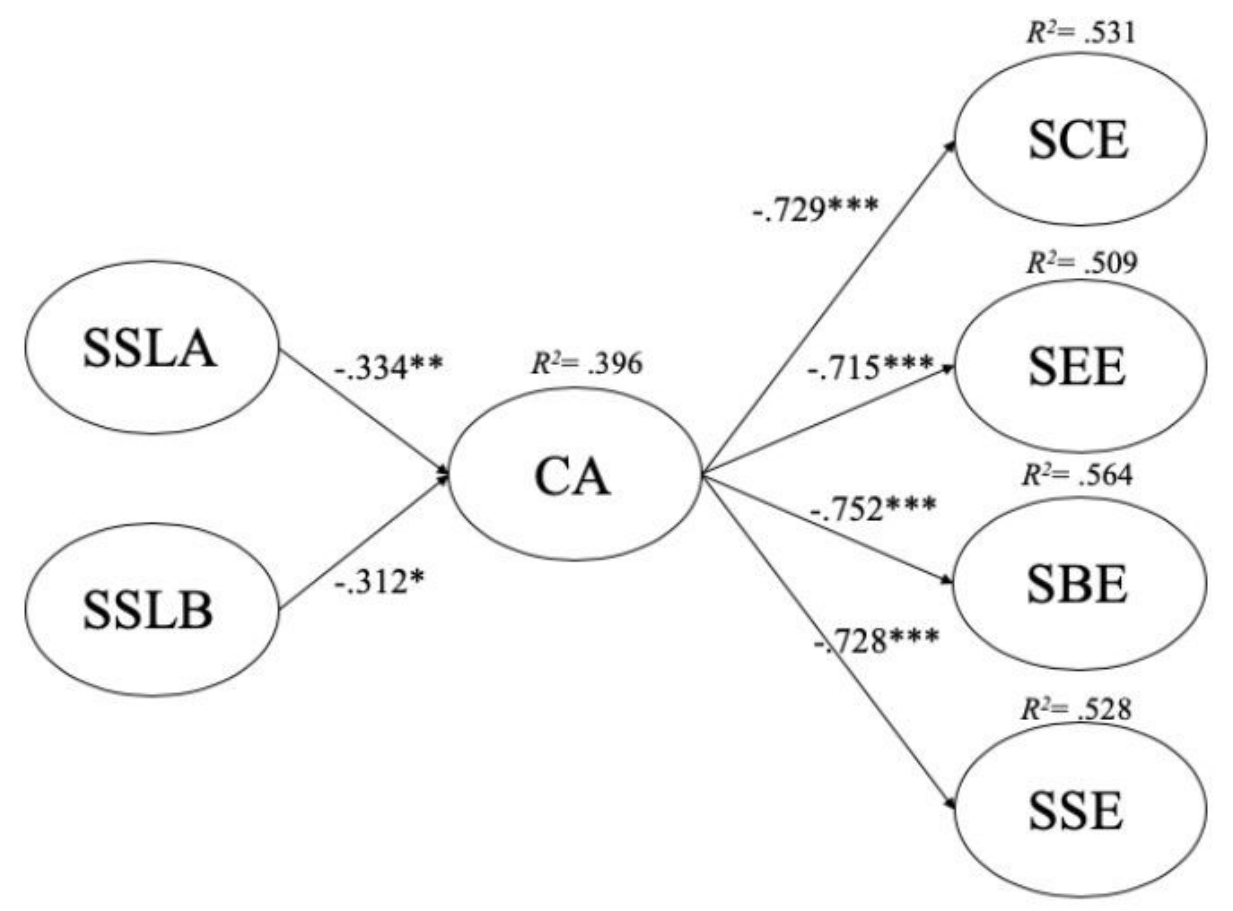

Figure 4

Verification of the research model 